\title{
Nanocrystalline oxide supercapacitors
}

\author{
Nae-Lih $\mathrm{Wu}^{*}$ \\ Department of Chemical Engineering, National Taiwan University, Taipei, Taiwan, ROC
}

\begin{abstract}
Two sets of $\mathrm{SnO}_{2}$-based supercapacitors (SCs) were synthesized and characterized. The first set, typical of double-layer (DL) capacitance, comprises Sb-doped $\mathrm{SnO}_{2}$ nanocrystallites synthesized by a sol-gel process. A surface-grafting technique was introduced to delay grain coarsening, giving rise to a maximum capacitance in $1 \mathrm{M} \mathrm{KOH}_{(\mathrm{aq})}$ of $16 \mathrm{~F} \mathrm{~g}^{-1}$ (or $64 \mathrm{~F} \mathrm{~cm}^{-3}$ ). The second set includes composite electrodes consisting of nanocrystalline $\mathrm{SnO}_{2}$ and $\mathrm{RuO}_{2}$ or $\mathrm{Fe}_{3} \mathrm{O}_{4}$ nanocrystallites, which are known to exhibit pseudocapacitance. $\mathrm{Fe}_{3} \mathrm{O}_{4}-\mathrm{SnO}_{2}$ composite electrodes exhibiting a capacitance of $33 \mathrm{Fg}^{-1}$ (or $\sim 130 \mathrm{~F} \mathrm{~cm}^{-3}$ ), at a voltage-sweeping rate of $50 \mathrm{mV} \mathrm{s}^{-1}$ in $1 \mathrm{M} \mathrm{Na}_{2} \mathrm{SO}_{4}(\mathrm{aq}$ ) were demonstrated. (c) 2002 Elsevier Science B.V. All rights reserved.
\end{abstract}

Keywords: Supercapacitor; Electrochemical capacitor; Double-layer capacitance; Pseudocapacitance; Nanocrystalline; Metal oxide

\section{Introduction}

Supercapacitor (SC), also known as electrochemical capacitor, is an unique electrochemical device designed to possess characteristics of high power density $\left(>1 \mathrm{~kW} \mathrm{~kg}^{-1}\right)$, high charge-discharge cycle life ( $>10^{4}$ cycles), and high discharge efficiency (>90\%). When incorporated into a battery-based power source, it adds the capability for meeting the burst power demands in applications such as electric vehicles. Two types of energy-storage mechanisms have been utilized in SC [1,2]. The double-layer (DL) storage mechanism involves charge separation at the electrode-electrolyte interface [3-7], while the Faradaic redox reaction of surface species gives rise to the so-called "pseudocapacitance" $[1,2,8-12]$. The DL capacitance has a typical value of $10-40 \mu \mathrm{F} \mathrm{cm}^{-2}$ of real surface, while pseudocapacitance may be 10-100 times greater. Irrespective of the charge-storage mechanism, large surface area and high conductivity are two essential properties of the electrode material for large capacitance.

Nanocrystalline metal oxides, many of which possess the characteristics of large surface area, high conductivity, electrochemical stability, and pseudocapacitive behavior, can have significant contribution to this technology. $\mathrm{SnO}_{2}$, for instance, has been used as an electrode material in solution decomposition of organics, due to its good chemical stability and high conductivity [14-16]. High surface area $\mathrm{SnO}_{2}$ has been synthesized via the sol-gel process [17-21]. Nanocrys-

${ }^{*}$ Tel.: +886-22-3635230; fax: $+886-22-3623040$.

E-mail address: nlw001@ccms.ntu.edu.tw (N.-L.Wu). talline $\mathrm{RuO}_{2}, \mathrm{IrO}_{2}$ and $\mathrm{Fe}_{3} \mathrm{O}_{4}$ prepared via solution chemistry have been shown to exhibit pseudocapacitance under certain conditions [8-13]. This paper describes the synthesis and characterization of two sets of $\mathrm{SnO}_{2}$-based electrodes. The first set, typical of DL capacitance, comprises Sb-doped $\mathrm{SnO}_{2}$ nanocrystallites synthesized by a sol-gel process. The second set includes composite electrodes consisting of nanocrystalline $\mathrm{SnO}_{2}$ in combination with ruthenium oxide or iron oxide nanocrystallites, which are known to exhibit pseudocapacitance.

\section{Experimental}

Sb-doped $\mathrm{SnO}_{2}$ xerogel powder was prepared as follows. Ammonia was introduced into an aqueous solution of $\mathrm{SnCl}_{4}$ to cause condensation. The gelatinous precipitate thus produced was peptized at $\mathrm{pH} \sim 10.0$. An alcoholic solution of $\mathrm{SbCl}_{3}$ that gives a final $\mathrm{Sb}: \mathrm{Sn}$ molar ratio of 0.06:1 was then added, resulting in another condensation. The supernatant liquid was decanted and fresh water was replenished. The cycle was repeated, in order to remove $\mathrm{Cl}^{-}$, until the solution $\mathrm{pH}$ reached $\sim 4.0$. Hydrous powder was prepared by drying the precipitate at $30^{\circ} \mathrm{C}$ under $75 \%$ humidity.

The xerogel powder was either directly calcined or subjected to a surface-grafting treatment prior to calcination. For the surface-grafting treatment, xerogel powder was allowed to react with hexamethyldisilazane (HMDS; $\left(\mathrm{Si}\left(\mathrm{CH}_{3}\right)_{3}\right)_{2} \mathrm{NH} ; 98 \%$ purity) in a closed container at $150{ }^{\circ} \mathrm{C}$ for $\sim 1 \mathrm{~h}$, during which period HMDS vaporized and reacted 
with the hydroxyl surface groups to form methyl siloxyl ones:

$2-\mathrm{OH}+\left[\mathrm{Si}\left(\mathrm{CH}_{3}\right)_{3}\right]_{2} \mathrm{NH} \rightarrow 2-\mathrm{OSi}\left(\mathrm{CH}_{3}\right)_{3}+\mathrm{NH}_{3}$.

For simplicity, a prefix "H-" will be given to powders that are pretreated with HMDS, while "U-" is given to those untreated. Calcination has mainly been carried out in flowing air.

For the $\mathrm{RuO}_{2}-\mathrm{SnO}_{2}$ composite electrodes, ruthenium oxide was loaded by an incipient-wetness method, in which aqueous solution of $\mathrm{RuCl}_{3}$ was added to the calcined $\mathrm{SnO}_{2}$ xerogel powder in the amount that is just sufficient to completely wet the powder. The wetted powders were finally calcined at $200^{\circ} \mathrm{C}$.

For $\mathrm{Fe}_{3} \mathrm{O}_{4}-\mathrm{SnO}_{2}$ electrodes, titanium foils were first coated with a porous conductive $\mathrm{Sb}$-doped $\mathrm{SnO}_{2}$ layer. The $\mathrm{Fe}_{3} \mathrm{O}_{4}$-on- $\mathrm{SnO}_{2}$ electrodes were then prepared by immersing the $\mathrm{SnO}_{2}$-coated $\mathrm{Ti}$ electrodes into a hot $\left(60^{\circ} \mathrm{C}\right)$ solution of $1 \mathrm{M} \mathrm{FeSO}_{4}(\mathrm{pH}=8.0)$. Oxygen was bubbled into the solution for $30 \mathrm{~min}$ to deposit $\mathrm{Fe}_{3} \mathrm{O}_{4}$.

The calcination and the resulted microstructural properties have been characterized by thermogravimetry (TG), nitrogen adsorption (ASAP2000, Micromeritics), transmission electron microscopy (TEM), and X-ray diffraction (XRD; Mac-Science/MXP). Cyclic voltammetry (CV) analysis was performed using an electrochemical analyzer (Eco Chemie PGSTAT30) and a plane-type capacitor cell, which comprises two planar electrodes each of which has a $1 \mathrm{~cm} \times 1 \mathrm{~cm}$ active area and a glass-fiber separator. Two electrolytes have been employed in the present studies, including aqueous electrolytes containing $1 \mathrm{M} \mathrm{KOH}$ and $1 \mathrm{M} \mathrm{Na}_{2} \mathrm{SO}_{4}$, respectively. The latter was used only for electrodes containing iron oxide. The electrodes comprise calcined powders and $3 \mathrm{wt} . \%$ PVDF binder, which were spread onto a Ti foil. The specific capacitance quoted in this paper for each electrode, $C_{\mathrm{e}}$, was determined by the equation $C_{\mathrm{e}}=2\left[\left(i_{\mathrm{c}}+i_{\mathrm{a}}\right) / 2\right] /(s / w)$, where $i_{\mathrm{c}}$ and $i_{\mathrm{a}}$ are, respectively, the currents at $0.0 \mathrm{~V}$ during the cathodic and anodic sweeps, $s$, the voltage-sweeping rate, and $w$, the total weight of the active material(s) in one electrode. The multiplication of two accounts for the fact that each of the electrodes forms one capacitor at the interface, and hence there are totally two serial capacitors in one cell.

\section{Results and discussion}

\section{1. $\mathrm{SnO}_{2}$ electrode}

Upon calcination, the microstructures of $\mathrm{SnO}_{2}$ xerogel evolve through the stages of dehydroxylation, crystallization, and grain coarsening [18,22]. Dehydroxylation commenced upon heating and extended up to $\sim 550^{\circ} \mathrm{C}$. Grain growth accelerated at temperatures above $300{ }^{\circ} \mathrm{C}$, resulting in ever decreasing surface area with increasing calcination temperature (Table 1). The fresh gel had an initial specific surface area of $240 \mathrm{~m}^{2} \mathrm{~g}^{-1}$, and lost more than $70 \%$ of its initial surface upon calcination at $500^{\circ} \mathrm{C}$ for $1 \mathrm{~h}$.

$\mathrm{CV}$ analysis has established that the oxide capacitors have an operating voltage range of at least $1.0 \mathrm{~V}$. Fig. 1 summarizes the capacitances of the U-powders (i.e. the xerogel powders not pretreated with HMDS) in $1 \mathrm{M} \mathrm{KOH}_{(\mathrm{aq})}$ as a function of calcination temperature. The capacitance

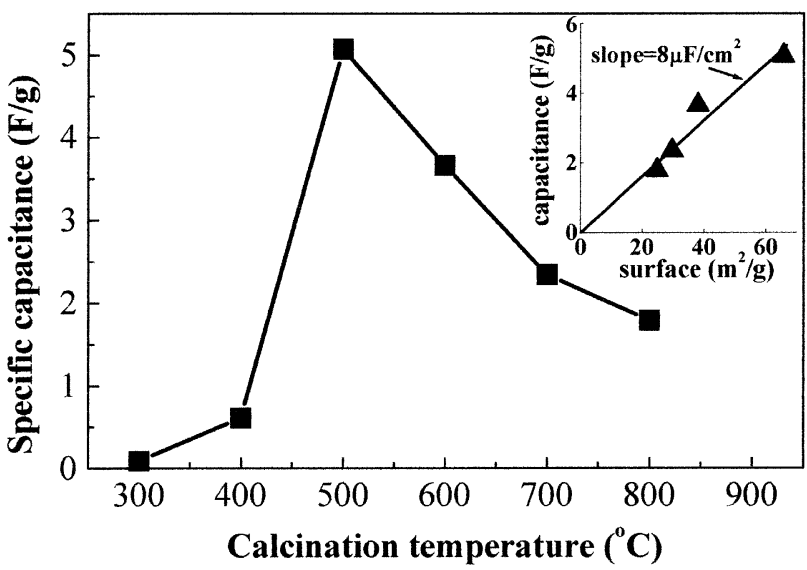

Fig. 1. Effect of calcination temperature on capacitance of Sb-doped $\mathrm{SnO}_{2} \mathrm{U}$-powders. The inset plots capacitance vs. specific surface area for U-powders calcined between 500 and $800^{\circ} \mathrm{C}$.

Table 1

Microstructural properties of $\mathrm{Sb}$-doped $\mathrm{SnO}_{2}$ xerogels

\begin{tabular}{|c|c|c|c|c|c|c|c|}
\hline & \multicolumn{7}{|c|}{ Calcination temperature $\left({ }^{\circ} \mathrm{C}\right)$} \\
\hline & 200 & 300 & 400 & 500 & 600 & 700 & 800 \\
\hline \multicolumn{8}{|l|}{ U-powder ${ }^{\mathrm{a}}$} \\
\hline Surface area $\left(\mathrm{m}^{2} \mathrm{~g}^{-1}\right)^{\mathrm{b}}$ & 210 & 190 & 105 & 66 & 38 & 30 & 25 \\
\hline Crystallite size $(\mathrm{nm})^{\mathrm{c}}$ & 2.3 & 2.9 & 3.5 & 5.8 & 9.4 & 11.3 & 14.4 \\
\hline \multicolumn{8}{|l|}{ H-powder ${ }^{a}$} \\
\hline Surface area $\left(\mathrm{m}^{2} \mathrm{~g}^{-1}\right)^{\mathrm{b}}$ & $\mathrm{NM}^{\mathrm{d}}$ & NM & NM & 133 & 102 & 103 & 75 \\
\hline Crystallite size $(\mathrm{nm})^{\mathrm{c}}$ & NM & NM & NM & 3.2 & 3.3 & 3.6 & 4.2 \\
\hline
\end{tabular}

${ }^{a}$ U-powder: xerogels untreated with HMDS prior to calcination; H-powder: xerogels pretreated with HMDS.

${ }^{b}$ BET surface area measured by $\mathrm{N}_{2}$ adsorption.

${ }^{c}$ Determined by XRD analysis using Debye-Scherrer equation and the full width at half maximum of $\mathrm{SnO}_{2}\left(\begin{array}{ll}1 & 10\end{array}\right)$ Bragg peak.

d Not measured. 


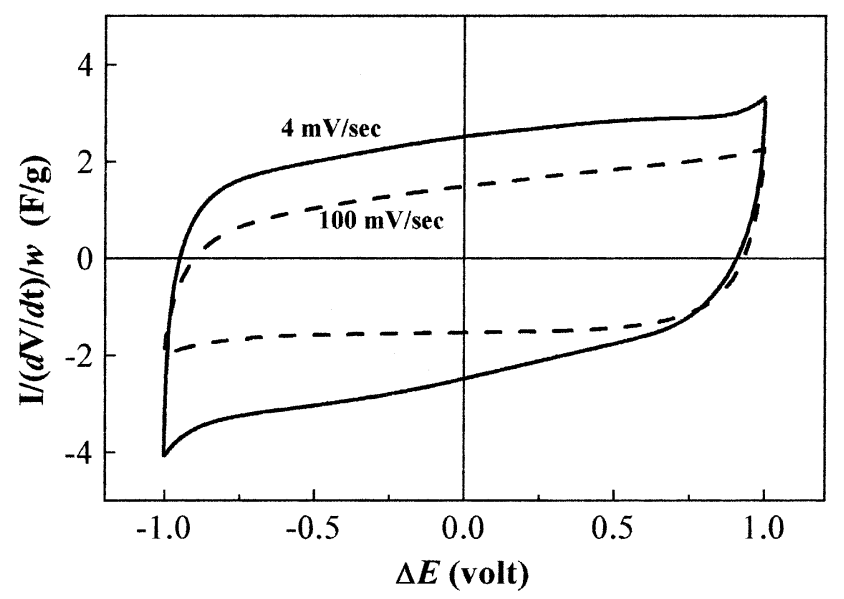

Fig. 2. Cyclic voltammograms of electrodes made of Sb-doped $\mathrm{SnO}_{2}$ U-powder calcined at $500^{\circ} \mathrm{C}$ (electrolyte: $1 \mathrm{M} \mathrm{KOH}_{(\mathrm{aq})}$ ). Here $w$ represents the weight of the active material in one electrode.

increases rapidly between 400 and $500{ }^{\circ} \mathrm{C}$ and then decreases at a slower rate with increasing calcination temperature, showing the maximum capacitance by calcination at $500^{\circ} \mathrm{C}$. The maximum capacitance is $\sim 5.0 \mathrm{Fg}^{-1}$ (or $20 \mathrm{~F} \mathrm{~cm}^{-3}$ ) (the geometric density of the xerogel is about 4.0 ), at the sweeping rate of $4 \mathrm{mV} \mathrm{s}^{-1}$. The BET surface area of this powder is $66 \mathrm{~m}^{2} \mathrm{~g}^{-1}$ (Table 1), which is translated to a surface-weighted specific capacitance of $7.6 \mu \mathrm{F} \mathrm{cm}^{-2}$ of real surface. The capacitance, nevertheless, decreases with increasing sweeping rate (Figs. 2 and 3).

For a semiconductor-electrolyte interface, the interfacial capacitance can be subdivided into serial capacitances including the space-charge capacitance on the semiconductor side and the DL capacitance on the electrolyte side. In a strong electrolyte, such as in the present case $(1 \mathrm{M}$ $\mathrm{KOH}_{(\mathrm{aq})}$ ), the capacitance of the entire system closely approximates to the space-charge value on the semiconductor side. In this case, the Mott-Schottky relationship

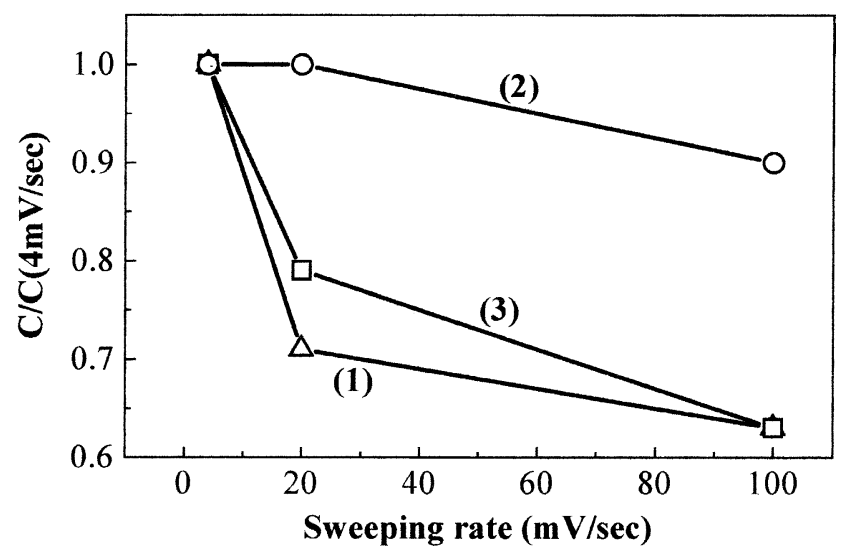

Fig. 3. Effect of $\mathrm{CV}$ sweeping rate on capacitance: (curve 1) $\mathrm{SnO}_{2}$ U-powder calcined at $500^{\circ} \mathrm{C}$; (curve 2) $\mathrm{H}$-powder calcined at $800^{\circ} \mathrm{C}$; (curve 3) $\mathrm{SnO}_{2}-\mathrm{RuO}_{2}$ (1.4 wt.\%) composite powder.
[23] predicts an interfacial capacitance (per unit surface area) to increase with the carrier density of the semiconductor. For a heavily defected semiconductor, such as most solution-derived polycrystalline conductive oxides, the effective carrier density is to a great extent affected by the presence of recombination centers associated with various crystallographic defects. The same effect extends to the grain conductivity, and hence to the responding behavior of the electrode to the charging-discharging protocol.

Accordingly, the rapid rise in the capacitance of the $\mathrm{SnO}_{2}$ xerogel electrodes with increasing calcination temperature from 300 to $500^{\circ} \mathrm{C}$ is consistent with the Mott-Schottky relationship, as one expects defect density to decrease and crystallinity to increase at higher calcination temperatures. The drop in capacitance above $500^{\circ} \mathrm{C}$, on the other hand, can be attributed to the reduction in total surface area caused by grain coarsening. One also notes that the capacitances based on unit surface area for the powders calcined at $600-800^{\circ} \mathrm{C}$ are essentially the same $\left(\sim 8 \mu \mathrm{F} \mathrm{cm}^{-2}\right)$ as that of the $500^{\circ} \mathrm{C}$ powder (inset in Fig. 1). This fact may indicate that calcination at these temperatures has little effect on removing intra-grain defects, presumably because the grains are large in these powders.

We previously demonstrated that pretreatment of hydrous xerogel powder with HMDS prior to calcination can be very effective for several oxide system in inhibiting grain coarsening upon calcination [21]. Table 1 compares the crystallite size and BET surface area of the U- and H-powders subjected to calcination at different temperatures. The delayed grain coarsening due to the HMDS treatment is evidenced.

The HMDS effect was reasoned as follows [21]. Upon calcination, condensation of hydroxyl groups proceeds prior to coarsening $[18,19]$. Condensation pulls together the constituent particles of the gel into a compact mass; and so the metal oxide crystals readily grow to a size much larger than that of the original particles. Two effects could result from the HMDS treatment. First, HMDS treatment helps to remove the surface hydroxyls and hence to isolate the hydrous particles upon calcination. This limits crystallization to take place in a very local scale, and hence helps to obtain small crystallites with a narrow size distribution. Secondly, decomposition of the surface-grafted siloxyls above $300{ }^{\circ} \mathrm{C}$ could produce secondary-phase particles, which serve as 'pins' to retard the advancement of grain boundaries during sintering.

The capacitance is negligible for the H-powder calcined below $500^{\circ} \mathrm{C}$. The powder calcined at 600 and $700^{\circ} \mathrm{C}$ exhibited capacitances of $\sim 7 \mathrm{Fg}^{-1}$ but their voltammograms showed severe inclination (Fig. 4), indicating large electrode resistances. TEM analysis revealed that these powders are fully crystallized. Thus, the poor performance exhibited by these powders cannot be attributed to low crystallinity, but to poor inter-grain conductivity, which is believed to have something to do with the secondary materials originating from the siloxyls. The capacitance increased rapidly as calcination temperature was raised to $800^{\circ} \mathrm{C}$. Maximum 


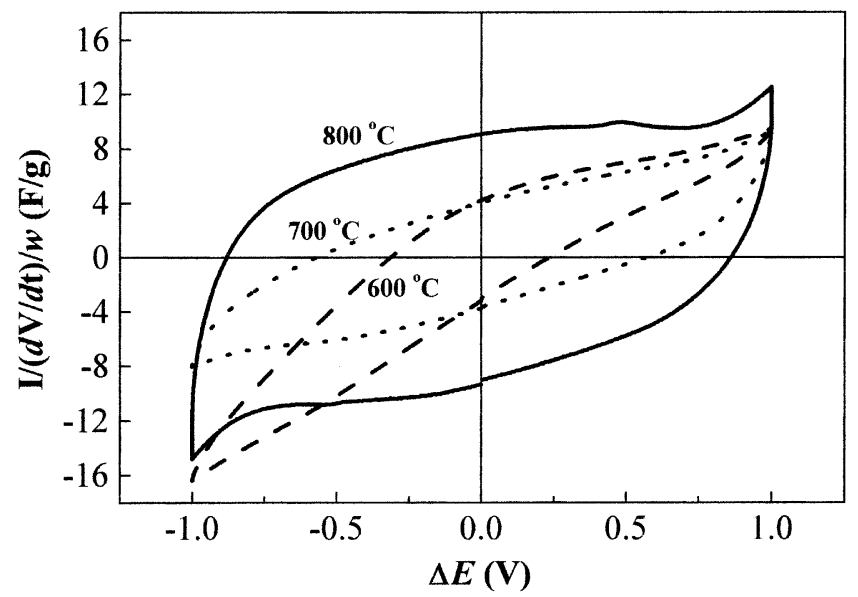

Fig. 4. Cyclic voltammograms of electrodes made of $\mathrm{Sb}$-doped $\mathrm{SnO}_{2}$ $\mathrm{H}$-powder calcined at $800^{\circ} \mathrm{C}$ (electrolyte: $1 \mathrm{M} \mathrm{KOH}_{(\mathrm{aq})}$ ). Here $w$ represents the weight of the active material in one electrode.

capacitances in the range of $10-16 \mathrm{Fg}^{-1}$, depending on heating rate, have been achieved by a final calcination at $800^{\circ} \mathrm{C}$ for $1 \mathrm{~h}$. One notices that the capacitance per unit surface area $\left(13-21 \mu \mathrm{Fcm}^{-2}\right)$ for these H-powders is much greater that that of the U-powder calcined $500^{\circ} \mathrm{C}$. That is, the HMDS treatment has allowed the $\mathrm{SnO}_{2}$ xerogel to crystallize in a way that gives less intra-grain defects and hence a higher effective carrier density than the conventional calcination protocol. This improvement is also reflected on the fact that the capacitance of the H-powder is rather insensitive to the sweeping rate (Fig. 3), as in great contrast with the U-powder electrodes.

\section{2. $\mathrm{SnO}_{2}-\mathrm{RuO}_{2}$ composite electrode}

Pseudocapacitance arising from under-potential deposition of $\mathrm{H}$ and $\mathrm{O}$ is known to result in extraordinary specific capacitances for $\mathrm{RuO}_{2}$. Application of this electrode material is severely hindered by its high cost. There have been studies in the literature on combining ruthenium oxide with a "second component" material to form composite electrodes with the intention to increase the dispersion of the oxide. The second-component materials include carbon, $\mathrm{VO}_{x}, \mathrm{TiO}_{2}, \mathrm{MoO}_{3}, \mathrm{SnO}_{2}$ and $\mathrm{CaO}$ [24-27]. Among them, $\mathrm{SnO}_{2}$ has the advantage of high conductivity.

Several composite electrodes containing a few percents $\left(\leq 3.3\right.$ wt. \%) of $\mathrm{RuO}_{2}$ in nanocrystallites supported on the $\mathrm{SnO}_{2}$ U-powder calcined at $500^{\circ} \mathrm{C}$ have been synthesized. Fig. 5 shows the voltammograms of the cell consisting of the electrodes containing $1.4 \mathrm{wt} . \% \mathrm{RuO}_{2}$, which have the largest capacitance among these composites. At the sweeping rate of $4 \mathrm{mV} \mathrm{s}^{-1}$, it exhibits a specific capacitance of $\sim 15 \mathrm{Fg}^{-1}$ (or $\sim 60 \mathrm{~F} \mathrm{~cm}^{-3}$ ), in comparison with $\sim 5 \mathrm{Fg}^{-1}$ (or $20 \mathrm{~F} \mathrm{~cm}^{-3}$ ) for the blank U-powder. If we attribute the capacitance enhancement relative to the blank U-powder electrode completely to the loaded $\mathrm{RuO}_{2}$, we determine the

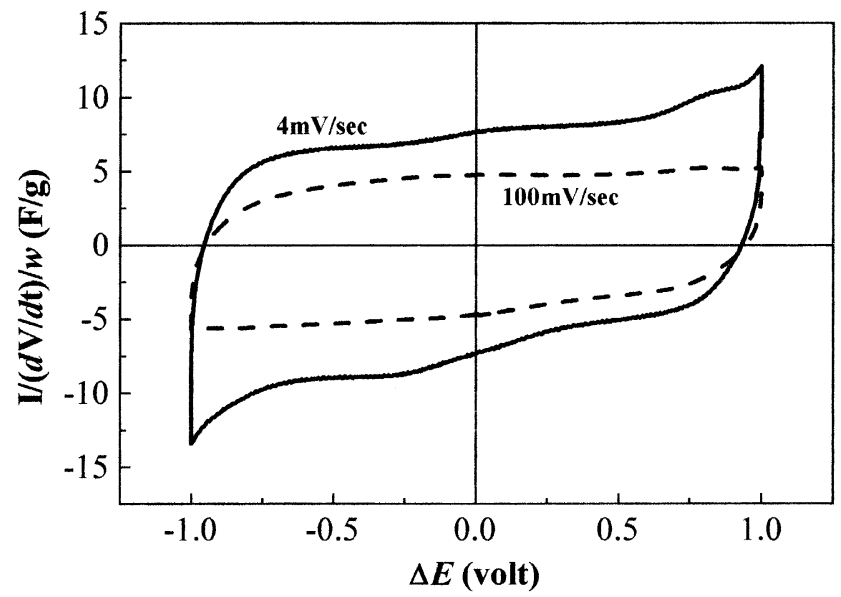

Fig. 5. Cyclic voltammograms of $\mathrm{SnO}_{2}-\mathrm{RuO}_{2}$ (1.4 wt.\%) composite electrode (electrolyte: $1 \mathrm{M} \mathrm{KOH}_{(\mathrm{aq})}$ ).

specific $\mathrm{RuO}_{2}$ capacitance to be $\sim 710 \mathrm{Fg}^{-1} \mathrm{RuO}_{2}$. Burke et al. [8] once determined a storage capacity of $\sim 13$ units of electronic charge per square nanometer for the surface processes. By applying this value, we estimate a specific surface area of $\sim 340 \mathrm{~m}^{2} \mathrm{~g}^{-1} \mathrm{RuO}_{2}$ in the present electrodes. This, in turn, is translated into a crystallite size of no greater than $3.0 \mathrm{~nm}$, assuming non-agglomerate crystallites.

The capacitance of the composite electrode was found to decrease at about the same rate as that of the blank substrate (curve 3, Fig. 3). This indicates that the $\mathrm{RuO}_{2}$ particles are uniformly dispersed throughout the skeleton of the xerogel substrate and they are well separated. As a consequence, the high-rate performance of the composite electrode would be determined mainly by the conductivity of the underlying $\mathrm{SnO}_{2}$ substrate.

A highly conductive substrate is also essential for SC based on $\mathrm{Fe}_{3} \mathrm{O}_{4}$ (magnetite), a newly discovered [13] pseudocapacitance material that has exhibited a capacitance as high as $480 \mathrm{Fg}^{-1}$ and an operating voltage range of at least $1.2 \mathrm{~V}$ in several aqueous electrolytes, including alkali

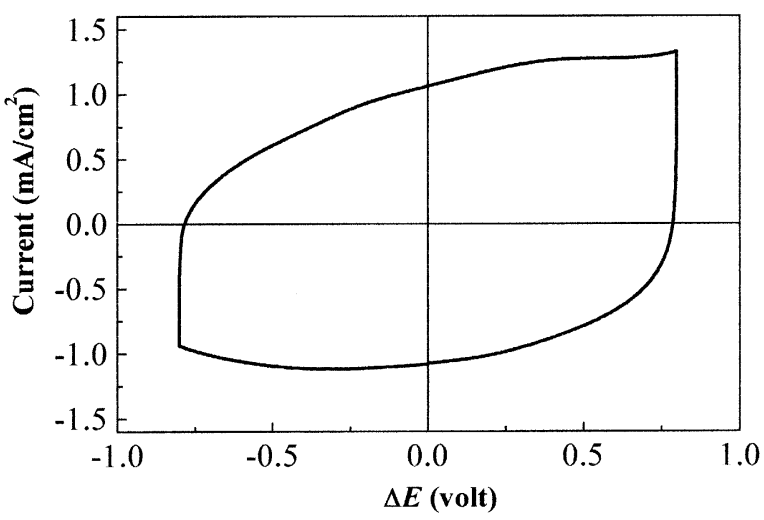

Fig. 6. Cyclic voltammogram of $\mathrm{SnO}_{2}-\mathrm{Fe}_{3} \mathrm{O}_{4}$ composite electrodes prepared by an electroless-plating process. 
Table 2

Comparison in capacitance among carbon and oxide materials

\begin{tabular}{|c|c|c|c|c|}
\hline & \multicolumn{2}{|l|}{$4 \mathrm{mV} \mathrm{s}^{-1}$} & \multicolumn{2}{|l|}{$100 \mathrm{mV} \mathrm{s}^{-1}$} \\
\hline & $\begin{array}{l}\text { Specific capacitance } \\
\left(\mathrm{Fg}^{-1}\right)\end{array}$ & $\begin{array}{l}\text { Capacitance density } \\
\left(\mathrm{F} \mathrm{cm}^{-3}\right)\end{array}$ & $\begin{array}{l}\text { Specific capacitance } \\
\left(\mathrm{Fg}^{-1}\right)\end{array}$ & $\begin{array}{l}\text { Capacitance density } \\
\left(\mathrm{F} \mathrm{cm}^{-3}\right)\end{array}$ \\
\hline $\mathrm{SnO}_{2}$ U-xerogel & 5.0 & 20 & 3.2 & 13 \\
\hline $\mathrm{SnO}_{2} \mathrm{H}$-xerogel & $10-16$ & $40-64$ & $9-14$ & $36-56$ \\
\hline $\mathrm{SnO}_{2}-\mathrm{RuO}_{2}$ & 15 & 60 & 9.6 & 38 \\
\hline $\mathrm{SnO}_{2}-\mathrm{Fe}_{3} \mathrm{O}_{4}$ & - & - & $33\left(50 \mathrm{mV} \mathrm{s}^{-1}\right)$ & $130\left(50 \mathrm{mV} \mathrm{s}^{-1}\right)$ \\
\hline Carbon & $20-200$ & $10-100$ & $10-100^{\mathrm{b}}$ & $5-50^{\mathrm{b}}$ \\
\hline
\end{tabular}

${ }^{\text {a }}$ Calculated based on the geometric densities of 4.0 and $0.5 \mathrm{~g} \mathrm{~cm}^{-3}$ for the oxide xerogel and carbon electrodes, respectively.

${ }^{b}$ The data are calculated based on a reduction of $50 \%$ in capacitance as the voltage-sweeping rate was increased from 4 to $100 \mathrm{mV} \mathrm{s}^{-1}$.

sulfates, sulfites and chlorides. Because of its low conductivity, the performance of this material depends very much on the electrode structure and composition. Combination with other conductive materials is essential to obtain large capacitance. $\mathrm{SnO}_{2}-\mathrm{Fe}_{3} \mathrm{O}_{4}$ composite electrodes were prepared by an electroless-plating process [28], as described in Section 2. Fig. 6 shows the voltammogram of the composite electrode in $1 \mathrm{M} \mathrm{Na}_{2} \mathrm{SO}_{4(\mathrm{aq})}$. The composite exhibits a specific capacitance of $33 \mathrm{Fg}^{-1}$ (or $\sim 130 \mathrm{~F} \mathrm{~cm}^{-3}$ ) at the scanning rate of $50 \mathrm{mV} \mathrm{s}^{-1}$.

\section{Summary}

Table 2 summarizes the capacitance of the oxide electrodes prepared in the present study. Also included are some data for carbon electrodes reported in the literature. The carbon-based DL SCs rely on their very large surface areas $\left(>1000 \mathrm{~m}^{2} \mathrm{~g}^{-1}\right)$ associated with micropores. While many of the reported microporous carbon materials are capable of exhibiting an specific capacitance exceeding $50 \mathrm{Fg}^{-1}$, their capacitance densities, i.e. capacitance per unit geometric volume of the active material, are much lower due to their low density, which is typically $\sim 0.5 \mathrm{~g} \mathrm{~cm}^{-3}$. The carbon electrodes also suffer from a rapidly reduced capacitance with increasing delivered power due to a large electrolyte resistance within micropores. Our studies on carbon black and graphitic electrodes not containing foreign conductive filler showed typically a reduction of more than $50 \%$ in capacitance as the $\mathrm{CV}$ sweeping rate was increased from 4 to $100 \mathrm{mV} \mathrm{s}^{-1}$ in $\mathrm{KOH}_{(\mathrm{aq})}$.

The performance of $\mathrm{SnO}_{2}$ xerogel electrode was remarkably improved as the material was subjected to the HMDS pretreatment, which, above all, allows for a crystallization process that helps to increase the carrier density of the oxide and hence to increase the space-charge capacitance. The $\mathrm{H}$-powders have a capacitance density greater than most of the reported carbon electrodes at high discharging rate $\left(\geq 100 \mathrm{mV} \mathrm{s}^{-1}\right)$.

The $\mathrm{SnO}_{2}-\mathrm{Fe}_{3} \mathrm{O}_{4}$ electrode, on the other hand, has a specific capacitance comparable with the carbon electrodes but a much higher capacitance density. In view of the low-cost and environmentally benign nature of the iron oxide, this composite electrode is believed to have a great potential for large-scale applications.

\section{Acknowledgements}

This work is supported by the National Science Council of the Republic of China under Contract no. NSC-892214-E-002-016.

\section{References}

[1] B.E. Conway, J. Electrochem. Soc. 138 (1991) 1539.

[2] S. Sarangapani, B.V. Tilak, C.-P. Chen, J. Electrochem. Soc. 143 (1996) 3791.

[3] D.C. Grahame, Chem. Rev. 41 (1947) 441.

[4] M.A.V. DeVanathan, B.V.K.S.R.A. Tilak, Chem. Rev. 65 (1965) 635.

[5] J. Tabuchi, T. Saito, Y. Kibi, A. Ochi, IEEE Trans. Comp. Hybrids Manuf. Technol. 16 (1993) 431.

[6] D. Qu, H. Shi, J. Power Sources 74 (1998) 99.

[7] M. Nakamura, M. Nakanishi, K. Yamamoto, J. Power Sources 60 (1996) 225.

[8] L.D. Burke, O.J. Murphy, J.F. O’Neill, S. Venkatesan, J. Chem. Soc., Faraday Trans. I 73 (1977) 1659.

[9] B.E. Conway, V. Birss, J. Wojtowicz, J. Power Sources 66 (1997) 1.

[10] J.P. Zheng, T.R. Jow, J. Electrochem. Soc. 142 (1995) L6.

[11] K.-K. Liu, M.A. Anderson, J. Electrochem. Soc. 143 (1996) 124.

[12] J. Mozota, B.E. Conway, Electrochim. Acta 28 (1983) 1.

[13] L.R. Shiue, N.L. Wu, D.S. Wu, Y.P. Lan, Patent pending, PCT/US01/00756.

[14] B. Correa-Lozano, Ch. Comninellis, A. De Battisti, J. Appl. Electrochem. 26 (1996) 683.

[15] B. Correa-Lozano, Ch. Comninellis, A. De Battisti, J. Appl Electrochem. 27 (1997) 970.

[16] L. Lipp, D. Pletcher, Electrochim. Acta 42 (1997) 1091.

[17] N.-L. Wu, L.F. Wu, Y.C. Yang, S.J. Huang, J. Mater. Res. 11 (1996) 813.

[18] N.-L. Wu, L.F. Wu, I.A. Rusakova, A. Hamed, A.P. Litvinchuk, J. Am. Ceram. Soc. 82 (1999) 67.

[19] S.-Y. Wang, N.-L. Wu, J. Non-Cryst. Solids 224 (1998) 259.

[20] N.-L. Wu, S.-Y. Wang, J. Mater. Sci. 34 (1999) 2807.

[21] N.-L. Wu, S.-Y. Wang, I.A. Rusakova, Science 285 (1999) 1375.

[22] N.-L. Wu, J.Y. Hwang, P.Y. Liu, C.Y. Han, S.L. Kuo, K.H. Liao, M.H. Lee, S.-Y. Wang, J. Electrochem. Soc. 148 (2001) 550.

[23] S.R. Morrison, Electrochemistry at Semiconductor and Oxidized Metal Electrodes, Plenum Press, New York, 1980. 
[24] Y. Sato, K. Yomogida, T. Nanaumi, K. Kobayakawa, Y. Ohsawa, M. Kawai, Electrochem. Solid-State Lett. 3 (2000) 113.

[25] C. Lin, J.A. Ritter, B.N. Popov, J. Electrochem. Soc. 146 (1999) 3155 .

[26] Y. Takasu, T. Nakamura, H. Ohkawauchi, Y. Murakami, J. Electrochem. Soc. 144 (1997) 2601.
[27] Y. Takasu, W. Sugimoto, T. Ohnuma, Y. Murakami, in: Proceedings of the 10th International Seminar on Double Layer Capacitors and Similar Energy Storage Devices, Deerfield Beach, FL, USA, 4-6 December 2000.

[28] M. Abe, Y. Tamaura, Jpn. J. Appl. Phys. (Part 2) 22 (1983) L511. 